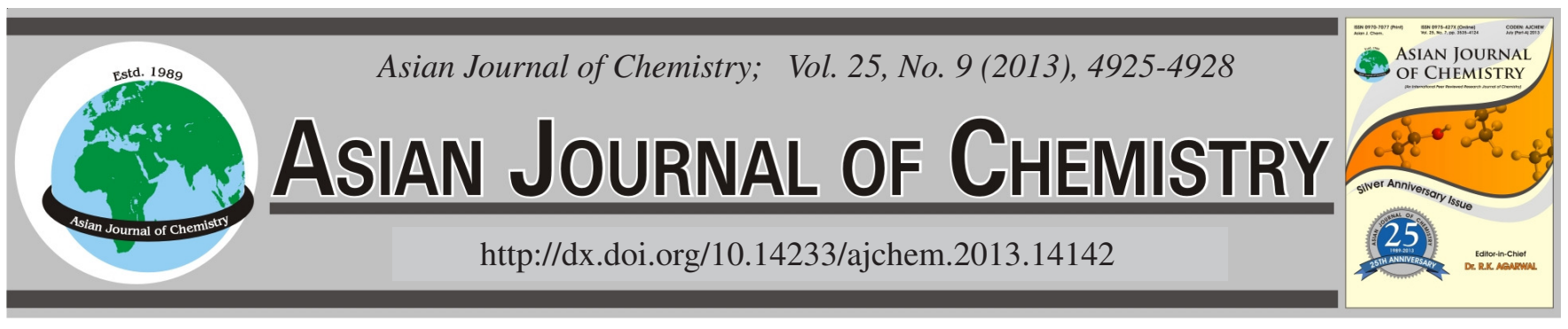

\title{
Synthesis and Characterization of a New Cyclophosphazene and Its Ruthenium Complex Derived from 1,10-Phenanthroline-5,6-diol
}

Gülnur Keser Karaoglan*, Ibrahim Erden and Nebahat Demirhan

Department of Chemistry, Faculty of Arts and Sciences, Yildiz Technical University, 34210 Esenler, Istanbul, Turkey

*Corresponding author: E-mail: gulnurkeser@ hotmail.com

(Received: 4 June 2012;

Accepted: 8 March 2013)

AJC-13104

A new spirocyclic phosphazene derivative has been synthesized from the reaction of 1,10-phenanthroline-5,6-diol with hexachlorocyclotriphosphazatriene in suitable conditions and the $\mathrm{Ru}(\mathrm{II})$ complex of the ligand was prepared and characterized. Synthesized compounds have been investigated with the methods of FTIR, ${ }^{1} \mathrm{H}$ NMR, ${ }^{31} \mathrm{P}$ NMR, UV-VIS, MS, fluorescence and elemental analysis.

Key Words: Spirocyclic phosphazene, Ruthenium complex, 1,10-Phenanthroline.

\section{INTRODUCTION}

In the last four decades, phosphazene derivatives attracted more attention due to considerable interest for a number of reasons i.e., (i) the general preparative chemistry of a structurally relative simple trinuclear compound with the phosphorous nuclei in different chemical environments; (ii) for producing inorganic polymers with different organic and inorganic side groups ${ }^{1}$; (iii) for the investigation of the stereogenic properties of phosphazenes ${ }^{2,3}$ and (iv) the further design of the highly selective anticancer ${ }^{4}$, antibacterial ${ }^{5}$ and anti $\mathrm{HIV}^{6}$ agents. On the other hand, they have also found applications in producing nonburning textile fibers, advanced elastomers ${ }^{7,8}$, rechargeable lithium batteries ${ }^{9,10}$ and besides their multidimensional use as biomedical materials ${ }^{11}$.

Cyclophosphazenes have attracted the attention of researchers for three main reasons. One, attention has centered on the substitution of the $\mathrm{P}-\mathrm{Cl}$ bonds of chlorocyclophosphaze with many nucleophilic reagents. The stereo- and regioselectivities involved in these reactions has been a subject of intense scrutiny. The usage of cyclophosphazenes as ligands for transition metals is another area of interest. Coordination through a ring nitrogen atom and/or an appropriately substituted ligand group can lead to a number of interesting structures $^{12}$.

A variety of cyclic phosphazene trimers containing the azido group with aryloxy, alkoxy or dialkylamino cosubstituents have been synthesized. Reaction leading to aryloxphosphazenes is the most numerous and intensively investigated in cyclophosphazene chemistry ${ }^{13-16}$.
In this work, a new spirocyclic phosphazene derivative has been synthesized from the reaction of 1,10-phenanthroline5,6-diol with hexachlorocyclotriphosphazatriene in suitable conditions and the $\mathrm{Ru}(\mathrm{II})$ complex of the ligand was prepared and characterized. Synthesized compounds have been investigated with the methods of FTIR, ${ }^{1} \mathrm{H}$ NMR, ${ }^{31} \mathrm{P}$ NMR, UV-visible, $\mathrm{MS}$, fluorescence and elemental analysis.

\section{EXPERIMENTAL}

All the chemicals were of the highest grade available. Hexachlorocyclotriphosphazatriene $\left(\mathrm{N}_{3} \mathrm{P}_{3} \mathrm{Cl}_{6}\right)$ was purchased from Aldrich and recrystallized from dry hexane followed by sublimation twice before use. Tetrahydrofuran was distilled from calcium hydroxide. All experimental manipulations were carried out under argon atmosphere. FTIR spectra were recorded as $\mathrm{KBr}$ disks on a Mattson 1000 FTIR spectrometer. ${ }^{31} \mathrm{P}$ NMR spectra were recorded with the use of Brucker AC$500 \mathrm{MHz}\left(\mathrm{CDCl}_{3}-d_{6}\right)$ spectrometer. The elemental analyses and mass spectra (MS) were determined in the TUBITAK Laboratory (Center of Science and Technology Research of Turkey). Melting points were measured with a BÜCHI melting point B-540 apparatus using a capillary tube. Fluorescence spectra were recorded on a "PTI C71 Time Resolved Spectrofluorometer".

Synthesis of 1,10-phenanthroline-5,6-dione: 1,10Phenanthroline ( $5 \mathrm{~g}$ ) was dissolved in portions during stirring in $30 \mathrm{~mL}$ of concentrated sulfuric acid in a $100 \mathrm{~mL}$ roundbottom flask equipped with a reflux condenser. Sodium bromide $(2.50 \mathrm{~g})$ was then added, followed by $15 \mathrm{~mL}$ of $70 \%$ nitric acid. The mixture was heated to boiling and then kept 
refluxing for 40 min heating was then reduced and the reflux condenser removed to allow the bromine vapors to escape during $15 \mathrm{~min}$ of gentle boiling. After being cooled the mixture was poured into $400 \mathrm{~g}$ of ice, carefully neutralized to $\mathrm{pH} 7$ with about $150 \mathrm{~mL}$ of $10 \mathrm{M}$ sodium hydroxide and allowed to stand for $0.5 \mathrm{~h}$. The turbid solution was filtered and the solids were extracted with $100 \mathrm{~mL}$ of boiling water. The insoluble material was removed from the cooled extract by filtration and the combined aqueous solutions were extracted with $5 \mathrm{~mL}$ $\times 100 \mathrm{~mL}$ dichloromethane. The organic phase was washed with $50 \mathrm{~mL}$ of water, dried over anhydrous sodium sulphate and evaporated under reduced pressure. The crystalline residue was recristalyzed from $400 \mathrm{~mL}$ of toluene to give the dione: $2.64 \mathrm{~g}(45 \%)$, yellow-orange needles, m.p. $257^{\circ} \mathrm{C}$, IR ( $\mathrm{KBr}$, $\left.v_{\max }, \mathrm{cm}^{-1}\right): 3060(\mathrm{Ar}-\mathrm{CH}), 1702(\mathrm{C}=\mathrm{O}), 1576.738(\mathrm{Ar}-\mathrm{CH})$.

Synthesis of 1,10-phenanthroline-5,6-diol $\left(\mathrm{C}_{12} \mathrm{H}_{8} \mathrm{~N}_{2} \mathrm{O}_{2}\right)$ : 1,10-Phenanthroline-5,6-dione ( $0.5 \mathrm{~g})$ and hydrazine sulphate $(1.1 \mathrm{~g})$ were mixed in water $(15 \mathrm{~mL})$ and kept in a boiling water bath for $c a .2 \mathrm{~min}$, until the vigorous evolution of the gas had ceased. Upon cooling the yellow solid was removed and washed with ethanol thoroughly to yield $83 \%$. The compound decomposed at $390{ }^{\circ} \mathrm{C}$ after sintering, consistent with the literature description). m.p. $280^{\circ} \mathrm{C}$, IR $\left(\mathrm{KBr}, \mathrm{v}_{\max }, \mathrm{cm}^{-1}\right): 3095$ (Ar-CH), $1626(\mathrm{C}=\mathrm{N}), 1576,738(\mathrm{Ar}-\mathrm{CH})$. Anal. calcd. (\%) for $\mathrm{C}_{12} \mathrm{H}_{8} \mathrm{~N}_{2} \mathrm{O}_{2} .0 .25 \mathrm{H}_{2} \mathrm{O}$ : C, 66.50; H, 3.95; N, 12.92. Found (\%): C, 66.15; H, 3.878; N, 13.03. FAB (+) mass spectrum: $\mathrm{m} / \mathrm{z}: 213\left[\mathrm{M}+\mathrm{H}^{1}\right]$.

Synthesis of tris $(9,10$-phenanthrolinedioxy $)$ cyclotriphosphazene $\left(\mathbf{C}_{36} \mathbf{H}_{18} \mathbf{N}_{9} \mathbf{O}_{6} \mathbf{P}_{3}\right): 0.1272 \mathrm{~g}(0.6 \mathrm{mmol})$ 1, 10phenanthroline-5,6-diol and $0.0696 \mathrm{~g}(0.2 \mathrm{mmol})$ hexachlorocyclotriphosphazene was dissolved in dry $50 \mathrm{~mL}$ THF. $0.42 \mathrm{~mL}$ ( $3 \mathrm{mmol}$ ) triethylamine and $0.007 \mathrm{~g}$ tetrabutylammonium bromide was mixed with the reaction mixture. The reaction mixture was stirred at argon atmosphere. The reaction time was controlled by TLC. The solvent was fitrated and solid was washed with cold water after dried. The yellow solid was obtained: Yield 0.025 g. $(16 \%)$; m.p. $205^{\circ} \mathrm{C}$, IR (KBr, $v_{\max }$, $\left.\mathrm{cm}^{-1}\right)$ : $3050(\mathrm{Ar}-\mathrm{CH}), 1167\left(\mathrm{P}-\mathrm{O}-\mathrm{C}_{\mathrm{arm}}\right), 1616\left(\mathrm{C}=\mathrm{N}_{\text {phen }}\right), 1242$ $\mathrm{P}=\mathrm{N}$. Anal. calcd. (\%) for $\mathrm{C}_{36} \mathrm{H}_{18} \mathrm{~N}_{9} \mathrm{O}_{6} \mathrm{P}_{3}(765.5 \mathrm{~g} / \mathrm{mol})$ : $\mathrm{C}$, 56.48; H, 2.37; N, 16.47. Found (\%): C, 55.82; H, 2.18; N, 15.97. FAB (+) MS: 765.41 $\left[\mathrm{M}^{+}\right]$. ${ }^{1} \mathrm{H}$ NMR : 7.69-7.8 ppm (m, Ar-CH), 8.4-9.1 ppm (m, Ar-CH). ${ }^{31} \mathrm{P}$ NMR $\left(\mathrm{CDCI}_{3}\right) \delta$ $38.2 \mathrm{ppm}(\mathrm{s})$.

Synthesis of $\mathbf{R u}($ II) complex: To prepare the $\mathrm{Ru}(\mathrm{II})$ complex, the ligand $(0.0053 \mathrm{~g}, 0.007 \mathrm{mmol})$ was dissolved in dry ethanol $(20 \mathrm{~mL})$ and $\mathrm{Ru}(\mathrm{bpy})_{2} \mathrm{Cl}_{2}(0.012 \mathrm{~g}, 0.021 \mathrm{mmol})$ in $10 \mathrm{~mL}$ of dry ethanol was added to this solution. The mixture was stirred at $90{ }^{\circ} \mathrm{C}$ for $3 \mathrm{~h}$. A dark-yellow precipitate was obtained when the solution was cooled room temperature. It was filtered off, washed with diethyl ether. Yield 0.022 g. (45 $\%$; m.p. $>350^{\circ} \mathrm{C}$. IR $\left(\mathrm{KBr}, \mathrm{v}_{\max }, \mathrm{cm}^{-1}\right): 1602\left(\mathrm{C}=\mathrm{N}_{\text {phen }}\right), 1102$ $(\mathrm{P}-\mathrm{N}), 1154\left(\mathrm{P}-\mathrm{O}-\mathrm{C}_{\mathrm{arm}}\right)$. Anal. calcd. $(\%)$ for $=\mathrm{C}_{66} \mathrm{H}_{42} \mathrm{~N}_{15} \mathrm{O}_{6} \mathrm{P}_{3} \mathrm{Ru}_{3}$ (1537.26 g/mol): C, 51.57; H, 2.75; N, 13.67. Found (\%): C, 51.82; H, 2.69; N, 13.72. ${ }^{1} \mathrm{H}$ NMR : 8.1-8.9 ppm (m, Ar-CH), 9.2-9.5 ppm (m, Ar-CH).

\section{RESULTS AND DISCUSSION}

The new phosphazene ligand was synthesized from reaction of hexachlorocyclotriphosphazene with 1,2-dihydroxy-1,10- phenanthroline in suitable conditions and the $\mathrm{Ru}(\mathrm{II})$ complex of the ligand was prepared and characterized as shown in Scheme-I. The starting compounds, 1,10-phenanthroline-5,6dione and 1,10-phenanthroline-5,6-diol were synthesized according to literature methods ${ }^{17,18}$. FTIR data gave further useful information on the structure of substances. Synthesis reaction of 1,10-phenanthroline-5,6-dione confirmed by the presence of strong $\mathrm{C}=\mathrm{O}$ at $1702 \mathrm{~cm}^{-1}, \mathrm{Ar}-\mathrm{CH}$ at 1576,738 , $3060 \mathrm{~cm}^{-1}$. 1,10-Phenanthroline-5,6-diol of the IR spectrum showed $3095\left(\right.$ Ar-CH), $1626(\mathrm{C}=\mathrm{N}), 1576,738(\mathrm{Ar}-\mathrm{CH}) \mathrm{cm}^{-1}$ peaks. This structure confirmed mass spectrum. The molecular ion peaks m/z 213[M $\left.+\mathrm{H}^{1}\right]$ was observed (Fig. 1).<smiles>C1=CC2=CCc3cccnc3C2N=C1</smiles>

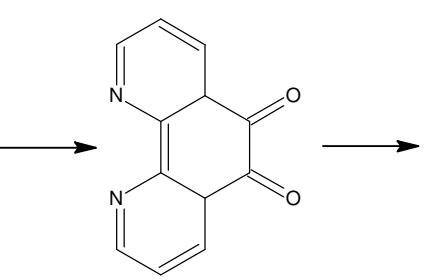<smiles>OC1=C2C=CC=NC2c2ncccc2C1O</smiles><smiles></smiles>

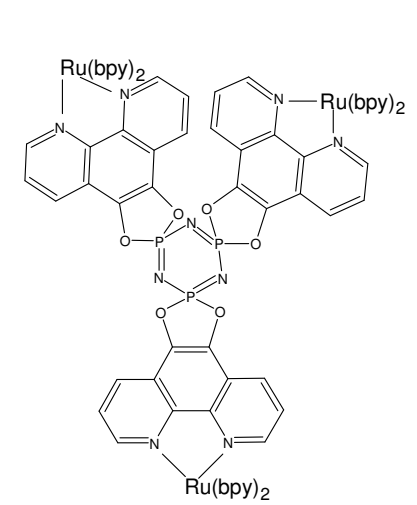

Scheme-I: Formation reaction of phosphazene ligand and structure of ruthenium complex

The phosphazene ligand $\left(\mathrm{C}=\mathrm{N}_{\text {phen }}\right)$ stretching bands appear at $1616 \mathrm{~cm}^{-1}$ for the free ligand; in the complex, these bands occur in approximately $1602 \mathrm{~cm}^{-1}$, showing that the nitrogen atom of the $\left(\mathrm{C}=\mathrm{N}_{\text {phen }}\right)$ group is coordinated to the metal ion.

Elementel analyses of the ligand and its Ru(II) complex show good agreement with the proposed structures. In the ${ }^{1} \mathrm{H}$ NMR spectrum of ligand in DMSO- $d_{6}$ the chemical shifts of $\left(\mathrm{CH}=\mathrm{N}_{\text {phen }}\right)$ protons are observed at $8.93 \mathrm{ppm}$, while the chemical shifts of $\left(\mathrm{CH}=\mathrm{N}_{\text {phen }}\right)$ protons are observed at 9.21 ppm in the $\mathrm{Ru}(\mathrm{II})$ complex.

The molecular peak $\mathrm{m} / \mathrm{z} 765.41\left[\mathrm{M}^{+}\right]$of the free ligand are present in the LC-MS spectra and support the proposed 


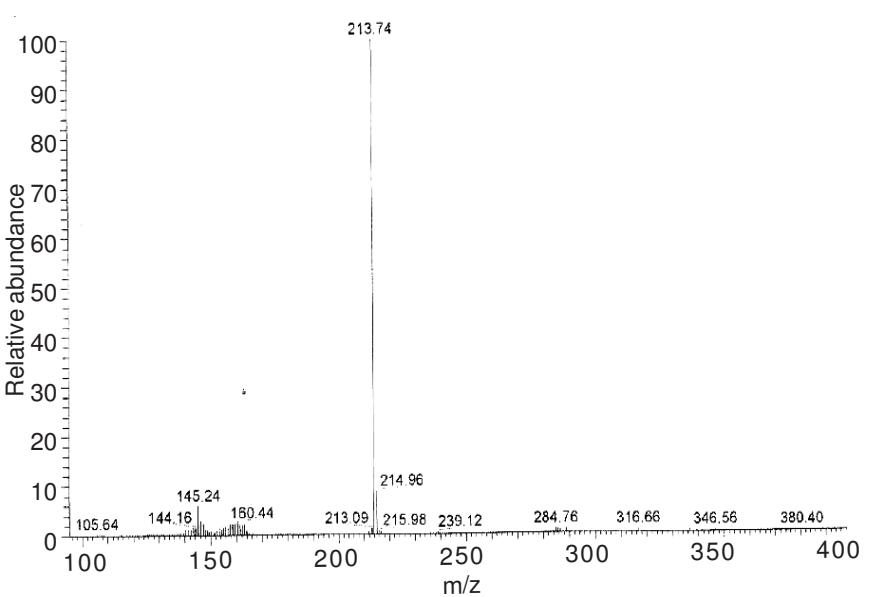

Fig. 1. Mass spectrum of 1,10-phenanthroline-5,6-diol

structures. The most intense peak at m/z $764.43\left[\mathrm{M}-\mathrm{H}^{1}\right]$ corresponds to the fragment $\left[\mathrm{C}_{36} \mathrm{H}_{17} \mathrm{~N}_{9} \mathrm{P}_{3} \mathrm{O}_{6}\right]$. Mass spectral data confirmed the proposed structure of phosphazene ligand (Fig. 2).

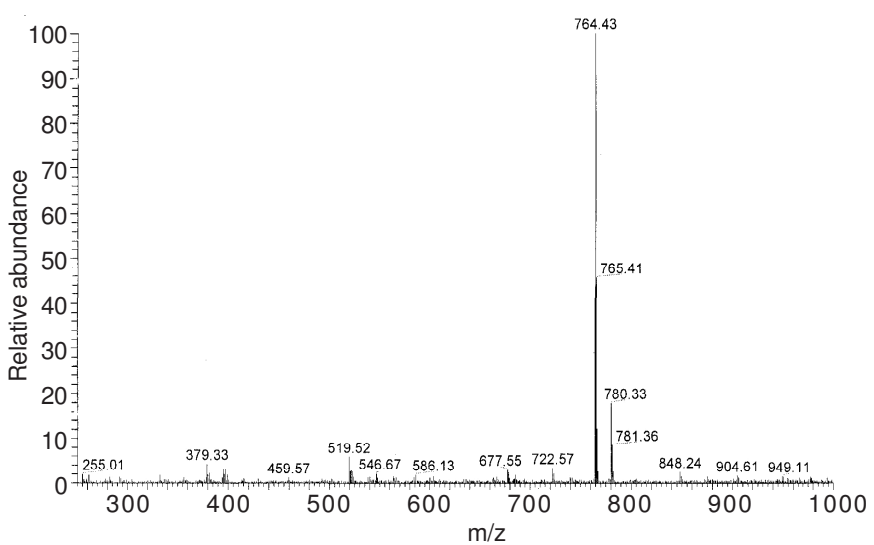

Fig. 2. Mass spectrum of phosphazene ligand

The UV-visible spectral data for the ligand (L) shows high energy band at $c a$. 225-260 $\mathrm{nm}$ and low energy band at approximately $260-290 \mathrm{~nm}$, while Ru-L complex shows low-energy band at $c a$. 225-260 nm and high energy band at approximately $260-330 \mathrm{~nm}$, due to $\mathrm{n}-\pi^{*}$ and $\pi-\pi^{*}$ transitions of the azomethine group in the ligands ${ }^{19,20}$. The peaks recorded in the spectrum Ru-L are broadened and slightly red-shifted (Fig. 3).

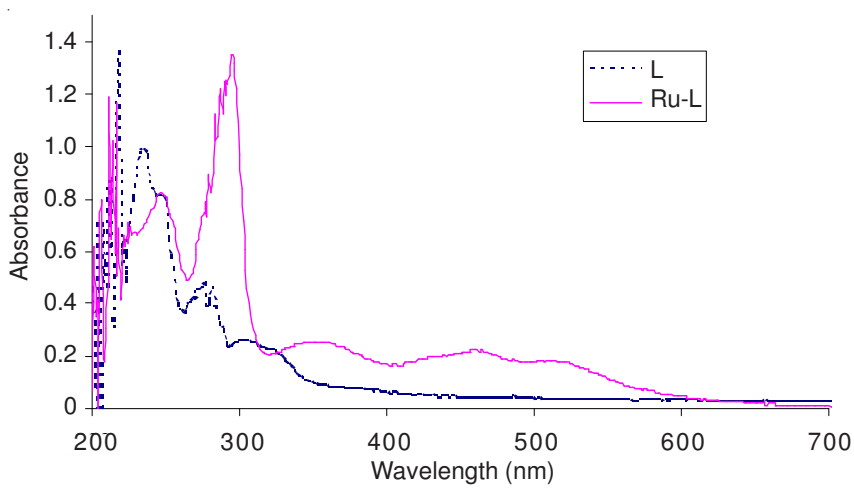

Fig. 3. UV-visible absorption spectra of ligand (L) and Ru(II) complex in ethanol
Fluorescence spectra were recorded on a "PTI C71 time resolved spectrofluorometer" including nanoflash nitrogen arc lamp and a stroboscopic detector by the Instrumental Analysis Laboratory of Chemistry Department of Yildiz Technical University, Istanbul. In this study, by the way of several experiments with different solvents as methanol, ethanol etc.; optimum fluorescence intensities of ligand and metal complex at room temperature $\left(25^{\circ} \mathrm{C}\right)$ were obtained in DMSO and therefore the samples were prepared in it. Fluorescence measurement settings were adjusted as $\lambda_{\mathrm{ex}}=337 \mathrm{~nm}$, int time: $0.1 \mathrm{~s}$, step size: $0.25 \mathrm{~nm}$, averages: 3 , slit widths: completely open and then they were compared to each other. Emission maxima of ligand and diluted and intense metal complex solutions were observed as $\lambda$ Em. Max Pho $=415 \mathrm{~nm} ; \lambda$ Em.Max RuPho $(2 \times$ $\left.10^{-5} \mathrm{M}\right)=391 \mathrm{~nm} ; \lambda$ Em.Max RuPho $\left(1 \times 10^{-4} \mathrm{M}\right)=383 \mathrm{~nm}$ (Fig. 4).

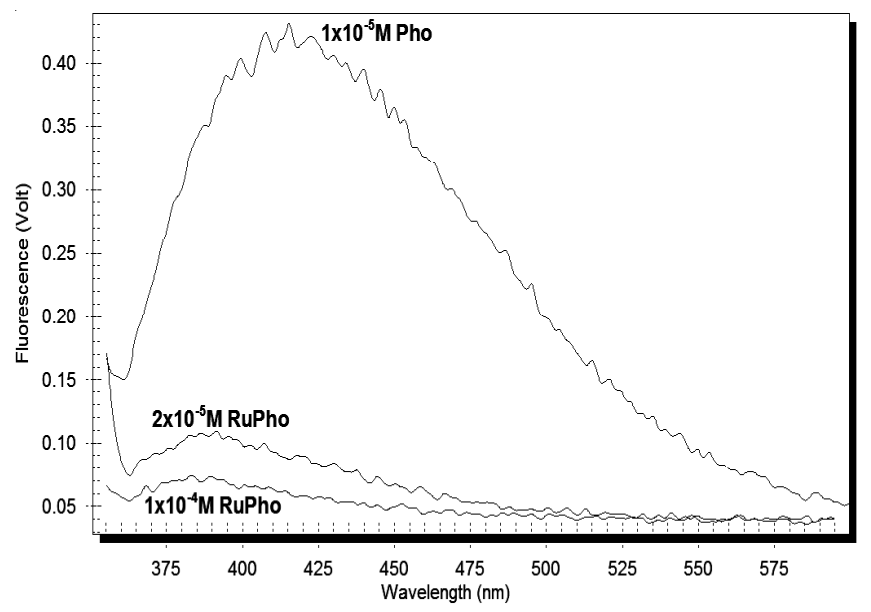

Fig. 4. Time resolved fluorescence spectra of Pho (ligand) and RuPho

The fluorescence spectra of ligand and metal complex showed that a strong static quenching and red shift in emission maxima occured as a result of ruthenium complex of phosphozene.

Separately, in comparison of diluted and intense concentrations of metal complexes, the fluorescence intensity difference between the same metal complex curves shows consisting of a dynamic quenching.

Consequently, all the two species give fluorescence emission and the ligand phosphozene has more strong fluorescence character relatively to its ruthenium complex.

\section{REFERENCES}

1. A. Uslu, S.J. Coles, D.B. Davies, R.J. Eaton, M.B. Hursthouse, A. Kilic and R.A. Shaw, Eur. J. Inorg. Chem., 1042 (2005).

2. S. Besli, S.J. Coles, D.B. Davies, R.J. Eaton, M.B. Hursthouse, A. Kilic, R.A. Shaw, G.Y. Ciftci and S. Yesilot, J. Am. Chem. Soc., 125, 4943 (2002).

3. S.J. Coles, D.B. Davies, R.J. Eaton, M.B. Hursthouse, A. Kilic, T.A. Mayer, R.A. Shaw and G. Yenilmez, J. Chem. Soc. Dalton Trans., 365 (2002).

4. H. Beak, Y. Cho, C. Lee and Y.S. Shon, Anti Cancer Drugs, 11, 715 (2000).

5. V. Konar, O. Yilmaz, A. Ozturk, S. Kirbag and M. Arslan, Bioorg. Chem., 28, 214 (2000).

6. K. Brandt, R. Kruszynski, T.J. Bartczak and I. Parwolik-Czomperlik, Inorg. Chim. Acta, 322, 138 (2001). 
7. J.E. Mark, H.R. Allcock and R. West, Inorganic Polymers, Printence-Hall, Englewood Cliffs, NJ (1992).

8. P.M. Blonsky, D.F. Shriver, P. Austin and H.R. Allcock, Solid State Ion, 18, 258 (1986).

9. D.F. Shriver and G.C. Ferrington, Chem. Eng. News, 63, 42 (1985).

10. H.R. Allcock, R. Eric, L. Didier, A. Mireille and C. Jean-Pierre, Macromolecules, 29, 1951 (1996).

11. H.R. Allcock and S. Kwon, Macromolecules, 19, 1502 (1986).

12. V. Chandrasekhar, K. Vivekanandan, S. Nagendran, G.T.S. Andavan, N.R. Weathers, J.C. Yarbrough and A.W. Cordes, Inorg. Chem., 37, 6192 (1998)
13. R.A. Pelc, K. Brandt and Z. Jedlinski, Phosphorus Sulfur Silicion Rel. Elem., 47, 375 (1990).

14. W.F. Deutsch and R.A. Shaw, J. Chem. Soc. Dalton Trans., 1757 (1988).

15. D. Kumar and A.D. Gupta, Macromolecules, 28, 6323 (1995).

16. H.R. Allcock, Chem. Rev., 72, 315 (1972).

17. J.E. Dickeson and L.A. Summers, Aust. J. Chem., 23, 1023 (1970).

18. J.-Z. Wu, H. Li, J.-G. Zhang and J.-H. Xu, Inorg. Chem. Commun., 5, 71 (2002).

19. R. Ziessel, Coord. Chem. Rev., 216-217, 195 (2001).

20. D.S. Tyson, C.R. Luman, X. Zhou and F.N. Castellano, Inorg. Chem., 40, 4063 (2001). 